\title{
The Enlightenment of Corpus-based Translation Studies for Chinese-English Translation of Tourism Texts in Xi'an
}

\author{
Tian'e Cheng \\ School of Foreign Languages \\ Northwest University \\ Xi'an, China 710127
}

\author{
Haixia Bai \\ School of Foreign Languages \\ Northwest University \\ Xi'an, China 710127
}

\begin{abstract}
Corpus-based translation study is a new research paradigm, which highlights the empirical study of translated texts from a micro level and is an effective way to explore the nature of translation. The present study focuses on translation strategies of tourism texts translation in Xi'an based on an analysis of tourism text corpus and recommends some specific translation strategies for translation of tourism texts in Xi'an from lexical level, syntactical level and textual level. The study results can help improve the quality of translated tourism texts in Xi'an to achieve the function of publicizing tourist attractions abroad.
\end{abstract}

Keywords-parallel corpus; comparable corpus; tourism texts; translation strategies

\section{INTRODUCTION}

At the beginning of the 1990s, a group of western translation theorists led by Mona Baker began to use corpus for translation studies, which received extensive attention from the translation circles. As an empirical research method, corpus-based translation studies is a new research paradigm, whose study subject is real bilingual corpus, based on datadriven quantitative analysis, taking probabilities and statistics as a means and emphasizing quantitative analysis at the micro level of translation texts ${ }^{[1]}$. Corpus-based translation studies established a corpus based on real translation corpora according to the specific research goals. With translation ontology as the research subject, corpusbased translation studies which combined intralingual comparison and interlingual comparison described and interpreted translation phenomena to explore the nature of translation from large-scale translation texts or translation language ${ }^{[2]}$. The description of translation facts by corpusbased translation studies includes lexicon, syntax, collocation, semantic prosody and discourse of translation texts, which is comprehensive and objective. At lexical level, it mainly analyzes data that reflected the application characteristics and distribution of the translation text words, such as the type/token ratio, standardized type/token ratio, lexical density, and word frequency listed in the vocabulary, frequency and use frequency of specific words. At syntactic level, it mainly focuses on analysis of data related to syntactic features of the translation text, such as average length of utterance, average length of segment, structure capacity, frequency and use frequency of the specific sentence structure. At collocation level, it mainly focuses on analysis of data reflecting the collocation significance ${ }^{[3]}$.

The corpus-based translation paradigm possesses obvious advantages. Corpus-based translation studies is based on data statistics and analysis of a large number of translation corpus or bilingual corpus, generalizes the regularity of translation language as well as translation process and has strong objective and scientific nature. The corpus-based translation studies not only attach importance to universals of translation language and translation norms, but also focus on the creativity in translation, translation language features and the style of translators. Inheriting the traditions of descriptive translation studies, the corpus-based translation studies accept the basic concepts and research methods of the cultural paradigm, but do not reject the linguistic paradigm. Bilingual special corpus has great potential value for both translation teaching and translation practice.

With the development of corpus-based translation studies, the academia began to introduce the theory and method of corpus into translation studies of tourism texts, which broadened the research channel for tourism translation, enhanced the empirical and objective nature of research, and promoted the development of the tourism translation studies. $\mathrm{Li}$ De-chao et al. (2009) discussed the guidance of comparison model of the parallel text for the translation of tourism texts from the discourse perspective, suggesting that reference to parallel texts could help translators produce idiomatic and functionally equivalent translations ${ }^{[4]}$. Hou Jin-rong (2011) analyzed the linguistic characteristics and discourse features of tourism texts based on corpus and pointed out that the C-E translation of tourism texts should strengthen the vocative function, intensify the textual cohesion as well as pay attention to the quality of language use in order to achieve the purpose of tourism promotion ${ }^{\text {[5] }}$. Cui Jian-zhou (2012) analyzed the stylistic features of tourism texts on web pages based on corpus, which provided effective guidance for the creation of good tourism destination images by publicity texts of web pages of scenic spot ${ }^{[6]}$. Li De-chao et al. (2015) analyzed the stylistic features of English tourism texts based on comparable 
corpus and found that the standardized type/token ratio of tourism translation texts was lower, the use of tense was rich and the writing style was formal and objective ${ }^{[7]}$. Xiong Bing (2016) discussed the lexical features of tourism texts and Chinese-English translation problems based on the corpus of Chinese-English tourism texts. He found that the lexical density of English translation of tourism texts was slightly lower, and the use frequency of first-person pronouns was significantly lower ${ }^{[8]}$.

\section{THE CHARACTERISTICS AND RESEARCH STATUS OF TOURISM TEXT TRANSLATION IN XI'AN}

The parallel texts and comparable texts in tourism texts corpora serve as a good translation template for C-E translation of tourism texts and provide translators with specific translation methods from lexicon, syntax and discourse levels, which regularize translators' translation acts and help translators, produce high quality English translations. Traditionally, most of the studies of linguistic features of tourism texts and their translation were based on certain translation theories (such as functional equivalence theory, Skopos theory, etc.) and the researchers' impressionistic or perceptive personal experience to explore the linguistic features and translation strategies of tourism texts. There has been no study of C-E translation strategies of tourism texts in $\mathrm{Xi}$ 'an based on corpus of tourism texts so far. The only few studies that discussed tourism text translation of individual scenic spots in Shaanxi province from Skopos theory, functional translation theory, communication theory, communicative translation theory et al are unsystematic because the researchers didn't classify the study subjects and failed to conduct the research in a hierarchical manner. Therefore, these studies are not systematic, comprehensive, scientific and reasonable enough and their results can neither provide theoretical guidance for $\mathrm{C}-\mathrm{E}$ translation of tourism texts in Xi'an, nor can they change the uneven status of the poor quality of English translations of the existing tourism texts, which makes the actual needs of $\mathrm{C}-\mathrm{E}$ translation norms of tourism texts in $\mathrm{Xi}$ 'an and related research seriously disjointed. Xi'an is rich in tourism resources, so the English translation of tourism texts serves as a bridge connecting tourist attractions in $\mathrm{Xi}$ 'an and foreign tourists. In order to promote the $\mathrm{C}-\mathrm{E}$ translation of tourism texts in Xi'an in a comprehensive, systematical, scientific and reasonable way, it is necessary to use special corpus of tourism texts to specifically guide the translator at lexicon, syntax and discourse level so that he or she can make use of the target language more normalized, standardized and internationalized and ensure the high quality of English translations of tourism texts.

\section{THE ENLIGHTENMENT OF CORPUS-BASED}

TRANSLATION STUDIES FOR C-E TRANSLATION OF TOURISM TEXT IN XI'AN

\section{A. The Enlightenment of Parallel Corpus for Tourism Texts Translation}

There are three main corpora for translation studies: parallel corpus, multilingual corpus, and comparable corpus.
The bilingual parallel corpus collects the source texts of a language and its corresponding translation texts, and consists of the source texts and the translation texts that have parallel correspondence relations between words, sentences or paragraphs. The multilingual corpus collects the source texts in two or more different languages. The comparable corpus collects the source texts of a language and texts translated from other languages. Compared with the common ChineseEnglish dictionaries, corpus can provide more abundant and informative materials, examples and references et al to help translators make appropriate choices.

The bilingual parallel corpus of tourism can provide translators with fresh, real and massive corpora related to attractions introduction, public signs in scenic spots, hotel promotion et al and an analysis of these tourism texts helps to reveal the universals and differences of linguistic features in lexicon, syntax, discourse, and writing style of Chinese and English tourism texts. With the help of corpus quantitative data analysis, some quantitative data information such as standardized type/token ratio of tourism texts, average length of words, average length of utterance, the occurrence frequency of part of speech can be obtained. The diction of English tourism texts are usually easy, rich, plain, focusing on textual cohesion and emphasizing vocative function while Chinese tourism texts are characterized with frequent use of quantifiers, fancy phrases, and recessive textual cohesion. Referring to parallel corpus of tourism texts can provide reference for lexical and syntactic transformation laws and mechanisms in the translation process of tourism texts. This research method based on bilingual parallel corpus can intuitively reveal the universals and differences in various aspects from lexicon to discourse of Chinese and English tourism texts and helps to refine the unique Chinese-English translation strategies of tourism texts.

\section{B. The Enlightenment of Comparable Corpus for Tourism Texts Translation}

Comparable corpus is composed of original English texts and translated English texts. Comparable corpus of tourism texts include both original English tourism texts and translated English tourism texts. Comparable corpus is usually used to analyze features of translated texts in comparison of the original English texts. With the ongoing development of corpus-based translation studies, an increasing number of corpuses of specific text-type have been developed in addition to literary texts. To date several corpuses of tourism texts have been created both at home and abroad [7]. An analysis of comparable corpus of tourism texts helps translators to understand differences between the original English tourism texts and the translated tourism texts, which may provide objective and practical foundation for C$\mathrm{E}$ translation of tourism texts [9]. Studies based on comparable corpus indicate that original English tourism texts highlight vocative functions of the texts. What's more, the words of the texts are simple and rich in part of speech, which is easy for the potential readers to understand. Therefore, when translating tourism texts, translators are advised to pay attention to the communicative and vocative 
functions of the texts, strengthen internal cohesion of the text, improve word choices and increase language vividness.

\section{Translation Strategies for Xi'an Tourism Texts}

Being publicity-oriented, tourism texts mainly focus on transmitting information and arousing the potential visitors' curiosity and travel interests. The main function of tourism texts is vocative function, supplemented with information function. Translators of Chinese tourism texts are suggested to value the vocative and informative functions of the translated tourism texts. Meanwhile, they should attach importance transmitting the exact information of tourism texts, using language that conforms to target language norms and that conforms to the target culture in order to express the meaning of the original texts. On the one hand, the cultural connotation of the original texts should be expressed exactly and naturally to the target readers. On the other hand, the translated version should produce the same effect on the potential readers as what the original text produces on the readers of the original text. Parallel corpus and comparable corpus of tourism texts provide a practical reference for the above mentioned translation goal.

1) Translation strategies at lexical level: Tourism texts feature a strong vocative function. The corpus of tourism texts shows that original English tourism texts are characterized by simple and concise word choice, direct expression which can encourage potential tourists to think and in the end make the decision to visited the publicized scenic spots. An analysis of tourism texts corpus can help translators understand the following language characteristics of tourism texts such as average word length and text difficulty, lexical variety, lexical density and information load, personal pronoun, high frequency words, theme expression as well as word choice features, providing reference for tourism text translation.

Studies of tourism text corpus indicate that monosyllabic words are frequently used in original English tourism texts to make the text less difficult. Less difficult tourist texts are easy for readers with different education levels and limited time to understand and gain necessary information within short time. Therefore, when translating tourism texts, translators had better use more monosyllabic words to facilitate readers' understanding of the translated texts. The high type-token ratio of original English tourism texts indicate that this type of text is rich in word variety, which suggests that translators using a variety of words to express the same or similar meaning to enrich word variety to conform to the reading habit of target readers. Text difficulty is to a certain degree related to word density which is a commonly used indicator for determining text difficulty. Generally speaking, higher word density indicates more difficult text and lower word density indicates less difficult text. In Chinese-English translation of tourism texts, simplification or desalination strategy can be used to make translated version conform to translation universals, namely, simplification, explicitation and normalization and make sure that the style of translated version is simple and direct, which conforms to lexical normalization and writing style of
English tourism texts. According to corpus of original English tourism texts, first person nominative pronoun is commonly used. The use of first and second person nominative pronouns can shorten the distance between text writer and text readers, increase language appeal, highlight the central role of tourists, make them come up with a sense of intimacy and motivate them to visit the tourist attractions and achieve the goal of publicizing tourist attractions. In translating tourism texts from Chinese into English, translators should consider using more first person pronouns to make tourism texts closer to potential readers and attract more foreign visitors in order to achieve the purpose of C-E translation of tourism texts.

2) Translation strategies at syntactic level: At syntactic level, translators are suggested using concise sentences to reduce text difficulty and achieve a much stronger effect. In organizing sentence structure, deductive strategies can be used more and importance should be attached to rigorous logic relationships among sentences. In addition, selective translation strategy, expansion and omission can be used to achieve vocative functions of the text in order to attract potential tourists. In the process of C-E translation of tourism texts active voice should be used more.

3) Translation strategies at textual level: Discourse is the highest level of language structure, which is an ultimate unit for effective communication. When translating Chinese tourism text into English, translators should strengthen discourse cohesion, paying attention to formal cohesion at textural level and semantic coherence in order to publicize tourism resources. Translators are also advised to exhibit their subjectivity to adjust the layout of the whole text and avoid the defects in arranging the structure, guarantee discourse cohesion to convey effective information, achieve equivalent communication to guarantee the acceptability of the translated texts in order to achieve successful communication.

\section{CONCLUSION}

The special corpus of tourism texts provides solid foundation of data analysis and theories for C-E tourism text translation. An analysis of such corpus can show writing techniques and language norms of the original English tourism texts and help translators learn about application strategies and features of different cultures from the corpus to strengthen variety of language and improve the quality translated texts. Translators can also analyze language features in collocation, figure of speech, sentence pattern and discourse structure, observe translation laws of the original language, compare different translation texts, language style and pattern, summarize translation strategies adopted in various original texts and to enhance interlingual conversion ability. 


\section{REFERENCES}

[1] Wang Kefei, Huang Libo. Corpus-based Translation Studies: Progress in Recent 15 Years. Foreign Language in China, 2008, 5(6),9-14.

[2] Wang Kefei, Huang Libo. Terms in Corpus-Based Translation Studies. Journal of Sichuan International Studies University, 2007, 23(6):101-105.

[3] Hu Kaibao. Corpus Translation Studies: Connotations and Implications. Journal of Foreign Languages, 2012, 35(5) 59-70.

[4] Li Dechao, Wang Kefei. A Model for Comparing Parallel Texts and Its Application in the English Translation of Chinese Tourist Brochures. Chinese Translators' Journal, 2009,4,54-58.

[5] Hou Jinrong. A Corpus-based Research on Language Features and Textual Analysis of Tourism Promotional Texts. Journal of Heze University. 2011, 33(6),124-128.

[6] Cui Jianzhou. Corpus-based Stylistic Analysis of the English Version Website Texts of the Tourist Attractions. Overseas English, 2012, 234-236.

[7] Li Dechao, Tang Fang. A Comparable Corpus-Based Study on Stylistic Features in Translated English Tourism Texts. Foreign Language in China. 2015,12(4): 88-96.

[8] Xiong Bing. A Corpus-based Study on Lexical Features of C-E Translations of Tourism Texts and C-E Tourism Translation. Journal of Central China Normal university (Humanities and Social Sciences), 2016,55(5), 94-103.

[9] Liang Xiaopeng, Kang Ning. On corpus-based approach to the translation of Chinese tourism texts. Journal of Qingdao University of Science and Technology(Social Sciences), 2010, 26(4), 115-117. 